\title{
Are Goal Intentions or Implementation Intentions Better Predictors of Health Behavior? A Longitudinal Study in Orthopedic Rehabilitation
}

\author{
Jochen P. Ziegelmann \\ Freie Universität Berlin
}

\author{
Aleksandra Luszczynska \\ University of Sussex and Warsaw School of Social Psychology
}

\author{
Sonia Lippke and Ralf Schwarzer \\ Freie Universität Berlin
}

\begin{abstract}
Objective: To compare the predictive power of goal intentions and implementation intentions. Design: Both constructs were expected to explain physical exercise at 3 points in time (with follow-ups at 6 and 12 months) in a sample of 368 persons participating in orthopedic rehabilitation. Results: Goal intentions and implementation intentions predicted exercise during rehabilitation. In contrast, goal intentions failed to predict exercise at later points in time, whereas implementation intentions continued to be associated with exercise 12 months later. Conclusions: Implementation intentions rather than goal intentions predict behavior as it becomes routine. As automatic processes such as behavior elicited by planning are largely age invariant, strengthening those processes might help to overcome volitional problems across all age groups represented in rehabilitation settings.
\end{abstract}

Keywords: physical exercise, intentions, planning, health behavior, age

In rehabilitation psychology and clinical psychology, various studies have dealt with self-regulatory and behavior-modification techniques that were designed to improve adherence to prescribed regimens such as self-control (Kanfer, 1977), behavioral programming (Green \& Washington, 2004), goal planning (McMillan \& Sparkes, 1999), motivational interviewing (Miller \& Rollnick, 2002), and treatment accommodation (Clay \& Hopps, 2003). In the present study, we adopt a social-cognitive perspective by examining intentionality as a precursor of such techniques.

A behavioral intention (e.g., "I intend to swim 30 minutes on most days of the week") is seen as a proximal precursor of action. Intention-based health-behavior theories, such as the theory of planned behavior (Ajzen, 2000), rely on the assumption that intentions constitute the best predictor of behaviors (see also Blanchard, Courneya, Rodgers, Daub, \& Knapik, 2002). Abraham and Sheeran (2000) expected behavioral intentions to account for $20 \%-25 \%$ of the variance in health behaviors (see also Sutton, 1998). Some researchers have questioned the proximal-predictor status of intentions (e.g., Schwarzer, 1992). Gollwitzer (1993)

Jochen P. Ziegelmann, Sonia Lippke, and Ralf Schwarzer, Department of Health Psychology, Freie Universität Berlin, Berlin, Germany; Aleksandra Luszczynska, Department of Psychology, School of Life Science, University of Sussex, Brighton, England, and Department of Psychology, Warsaw School of Social Psychology, Warsaw, Poland.

This research was supported by Deutsche Forschungsgemeinschaft (German Research Foundation) Grant GK 429/2-03 to Jochen P. Ziegelmann. We thank the staff of Zentrum für Ambulante Rehabilitation Gartenstrasse GmbH (Outpatient Orthopedic Rehabilitation Center), Berlin, Germany, for their cooperation.

Correspondence concerning this article should be addressed to Jochen P. Ziegelmann, PhD, Department of Health Psychology, Freie Universität Berlin, Habelschwerdter Allee 45, 14195 Berlin, Germany. E-mail: jochenzi@zedat.fu-berlin.de made a distinction between goal intentions and implementation intentions to signify different mind-sets and different levels of proximity to action. Goal intentions specify what people want to do within a certain time period. In contrast, implementation intentions (or action plans) refer in more detail to the when, where, and how of future action.

Intentions are more likely to be translated into action when a person develops a clear scenario of the circumstances under which the aspired action is to be performed (Gollwitzer, 1993; Leventhal, 1970). Action planning is more than an extension of an intention because it includes situation parameters (when, where) and a preprogrammed sequence of action (how). Action planning is supposed to be more effective than intentions when it comes to the likelihood of performance and speed of performance, mainly because the behavior is being elicited when the relevant situational cues are encountered. People do not forget their intentions easily when they are specified in a when, where, and how manner (for an overview and meta-analyses, see Gollwitzer \& Sheeran, 2006; Sheeran, 2002). Therefore, an implementation intention is a construct more proximal to behavior than a goal intention is.

Although studies provide evidence for the positive effects of simple plans (Gollwitzer, 1999; Luszczynska \& Schwarzer, 2003; Sheeran, 2002), the effects have often dealt with short-term behavior changes that should be performed on a regular basis. Milne, Orbell, and Sheeran (2002) used implementation intentions to increase subsequent exercise behavior. Participants who made implementation intentions were more likely to exercise 2 weeks later than were control group members who were equally motivated to exercise but who did not specify their implementation intentions. There is, however, growing evidence suggesting that interventions designed to improve implementation intentions have only a weak effect on long-term changes in physical activity among rehabilitation participants (cf. Jackson et al., 2005). There- 
fore, researchers should further investigate which properties of implementation intentions are crucial for its effectiveness.

Individuals form their own implementation intentions in everyday life. Similar to goal intentions, implementation intentions may be measured by means of self-reports. Because previous studies have experimentally induced intentions, researchers need to examine whether longitudinal research designs can replicate the evidence for the case of spontaneous intentions in daily life. Selfreported implementation intentions have been found to predict physical activity after cardiac rehabilitation (Luszczynska, 2006; Sniehotta, Schwarzer, Scholz, \& Schüz, 2005).

We investigated the role of goal intentions and implementation intentions (planning) in the prediction of physical exercise in a sample of 368 persons who were discharged from orthopedic rehabilitation. Both constructs were planned to account for the variance in physical exercise at three points in time: after completing a 3-week outpatient orthopedic rehabilitation (Time 1 [T1]), at a follow-up in 6 months (Time 2 [T2]), and at a follow-up in 12 months (Time 3 [T3]). We hypothesized that planning would be a better predictor than goal intentions at all three points in time over the 1-year period.

\section{Method}

\section{Participants and Procedure}

The study was conducted in an outpatient orthopedic rehabilitation center, where participants received daily exercise therapy. The participants' costs were covered by their health insurance. They were admitted because of musculoskeletal ailments, such as back pain (51.1\%), disk disorders $(39.1 \%)$, joint conditions $(18.5 \%)$, and injuries (10.3\%). Functional capacities were assessed with the 12-Item Short-Form Health Survey (SF-12; Ware, Kosinski, \& Keller, 1996). The sample had a mean of 37.4 $(S D=9.4)$ on the SF-12 physical component score as well as a mean of $50.5(S D=10.8)$ on the SF-12 mental component score (higher scores indicate better health). SF-12 values were similar to the scores of the German norm sample of individuals with arthritis, which has a mean of $39.7(S D=10.7)$ on the physical component score as well as a mean of $49.8(S D=9.5)$ on the mental component score (Bullinger \& Kirchberger, 1998). Regarding chronicity, participants reported a mean duration of their medical condition of 5.9 years $(S D=8.4)$. Participants expected to regain their previous levels of physical fitness. The aim of rehabilitation was mainly to improve fitness $(69.6 \%)$, to improve flexibility and muscular performance (63.3\%), to strengthen and stretch muscles (62.2\%), and to reduce bodily pain $(53.0 \%)$.

The study was advertised, and volunteers signed up for participation. They were told that the study was designed to examine volatility in adherence and self-regulatory problems. The participants had to meet the inclusion criteria of being capable of exercising on their own and of being able to fill out a questionnaire. To ensure anonymity and to encourage frank responses, all study materials had a code number instead of the participant's name. After providing informed consent, 637 persons were assessed after completing a 3-week outpatient orthopedic rehabilitation (T1). There were two postal follow-up assessments, one each at 6 months (T2, $n=495$, $77.9 \%$ ) and 12 months (T3, $n=371,58.4 \%$ ) after discharge. The final longitudinal sample on which the analyses were based consisted of 368 participants who provided data at all three measurement points. No significant differences on baseline measures of intention and planning and prerehabilitation exercise were revealed when we compared participants who did not respond to the follow-up with those who completed all assessments.

The sample had a mean age of 47.4 years $(S D=11.7$; range $18-80$ years), consisted primarily of women $(62.2 \% ; 37.8 \%$ men). Of the participants, $72.4 \%$ were living with a partner, and $70.5 \%$ were employed.

\section{Measures}

Goal intentions to perform physical activities were assessed with three items: "I intend to exercise as part of my daily routine," "I intend to exercise as part of my daily locomotion (e.g., cycling)," and "I intend to exercise as part of my leisure time." Implementation intentions were measured with the three items: "I have already planned precisely when to exercise," "I have already planned precisely where to exercise," and "I have already planned precisely how to continue exercising even when I feel limited by poor health." Answers were scored on a 4-point scale with not at all true, not true, a little true, and absolutely true.

Three domains of physical exercise were taken into consideration: (a) fitness activities, (b) exercises to train muscle strength, and (c) game sports, such as volleyball or golf. We asked (a) how many days did an individual perform the activity in question during the last week and (b) how many hours and minutes per session did he or she perform the activity. For each domain, exercise amount was computed by multiplying exercise days per week by minutes per exercise episode (e.g., Bernstein et al., 1998). The three domains were added to a sum score. Physical exercise was assessed right after rehabilitation (T1) and twice later (T2 and T3). Outliers were recoded to a value of $500 \mathrm{~min}$, which resulted in a distribution ranging from 0 to 500 min (see Table 1). Both subjective physical and mental health were assessed at discharge with the SF-12 (Ware et al., 1996).

Table 1

Descriptive Statistics of Study Variables

\begin{tabular}{|c|c|c|c|c|c|c|}
\hline \multirow[b]{2}{*}{ Variable } & \multicolumn{2}{|c|}{ Time 1} & \multicolumn{2}{|c|}{ Time 2} & \multicolumn{2}{|c|}{ Time 3} \\
\hline & $M$ & $S D$ & $M$ & $S D$ & $M$ & $S D$ \\
\hline Intention daily routines & 3.72 & 0.59 & 3.51 & 0.74 & 3.49 & 0.81 \\
\hline Intention daily locomotion & 3.67 & 0.64 & 3.57 & 0.73 & 3.57 & 0.72 \\
\hline Intention leisure time & 3.76 & 0.49 & 3.60 & 0.69 & 3.54 & 0.72 \\
\hline Planned when to exercise & 3.33 & 0.88 & 3.18 & 0.99 & 3.11 & 1.04 \\
\hline Planned where to exercise & 3.54 & 0.75 & 3.36 & 0.95 & 3.28 & 1.00 \\
\hline Planned how to exercise & 3.23 & 0.89 & 2.90 & 1.09 & 2.93 & 1.07 \\
\hline Exercise (min/week) & 159.20 & 153.40 & 180.70 & 158.80 & 185.60 & 168.20 \\
\hline
\end{tabular}

Note. $\quad N=368$. Except where indicated, values correspond to the following scale: $1=$ not at all true, $2=$ not true, $3=$ a little true, $4=$ absolutely true. Time $1=$ initial assessment period following completion of a 3-week rehabilitation; Time $2=6$ months after Time 1 ; Time $3=12$ months after Time 1 . 


\section{Data Analysis}

Multivariate repeated measures analysis (SPSS Version 12) was used to determine whether the two sets of items changed over time. To compare the associations between the two kinds of intentions with the physical exercise criterion, we specified a three-wave multiple-indicator structural equation model (AMOS 5; Arbuckle, 2003). The latent variable identified as goal intentions was established with the three intention items. Correspondingly, the implementation intentions construct was set up with the three planning items. Physical exercise was a manifest variable.

\section{Results}

Table 1 provides a summary of the means and standard deviations of all 21 variables. All item means are above the average of their theoretical scale mean of 2.5, indicating that the participants were generally highly motivated to perform physical exercise. Over time, goal intentions decreased, $F(6,15)=8.09, p<.01, \lambda=$ .94 , as determined by multivariate repeated measures analysis. Implementation intentions declined as well, $F(6,15)=7.16, p<$ $.01, \lambda=.94$. In contrast, exercise levels increased, $F(2,74)=$ $4.35, p<.05, \eta^{2}=.01$. Pairwise comparisons revealed that the difference between $\mathrm{T} 2$ and T3 exercise was not significant as opposed to the difference between T1 and T3 $(p<.01)$, and the difference between T1 and T2 $(p<.05)$. Thus, both goal intentions and implementation intentions decreased, whereas exercise activity increased.

To explore the predictive value of intentions on exercise behavior, we used a structural equation model with a cross-lagged panel design, which allowed cross-sectional and longitudinal predictions of $\mathrm{T} 2$ exercise by $\mathrm{T} 1$ goal intentions and $\mathrm{T} 1$ implementation intentions and of $\mathrm{T} 3$ exercise by $\mathrm{T} 2$ goal intentions and $\mathrm{T} 2$ implementation intentions. However, the analysis rendered all longitudinal paths insignificant, leaving only stability coefficients and a chain of cross-sectional prediction models (Figure 1). The model provided a satisfactory fit to the data, $\chi^{2}(177, N=368)=465.9$, $p<.01 ; \chi^{2} / d f=2.63$; Tucker-Lewis index $=.87$; comparative fit index $=.90$; root-mean-square error of approximation $=.07$.

The bias-free intercorrelations between the two kinds of intention constructs were $.28, .28$, and .29 at $\mathrm{T} 1, \mathrm{~T} 2$, and $\mathrm{T} 3$, respectively (all intercorrelations are significant at $p<.05$ ). The path coefficients from goal intentions to exercise were $.13(p<.05), .12$ $(p<.05)$, and $.02(n s)$, whereas the path coefficients from implementation intentions to exercise were $.12(p<.05), .28(p<.001)$, and $.32(p<.001)$. At T1, $4 \%$ of the exercise variance was accounted for, as opposed to $16 \%$ and $29 \%$ at $\mathrm{T} 2$ and $\mathrm{T} 3$, respectively. Past behavior (path coefficient $=.38, p<.001$ ) and current planning (path coefficient $=.32, p<.001$ ) contributed about equally to the explained variance at $\mathrm{T} 3$, whereas intention did not

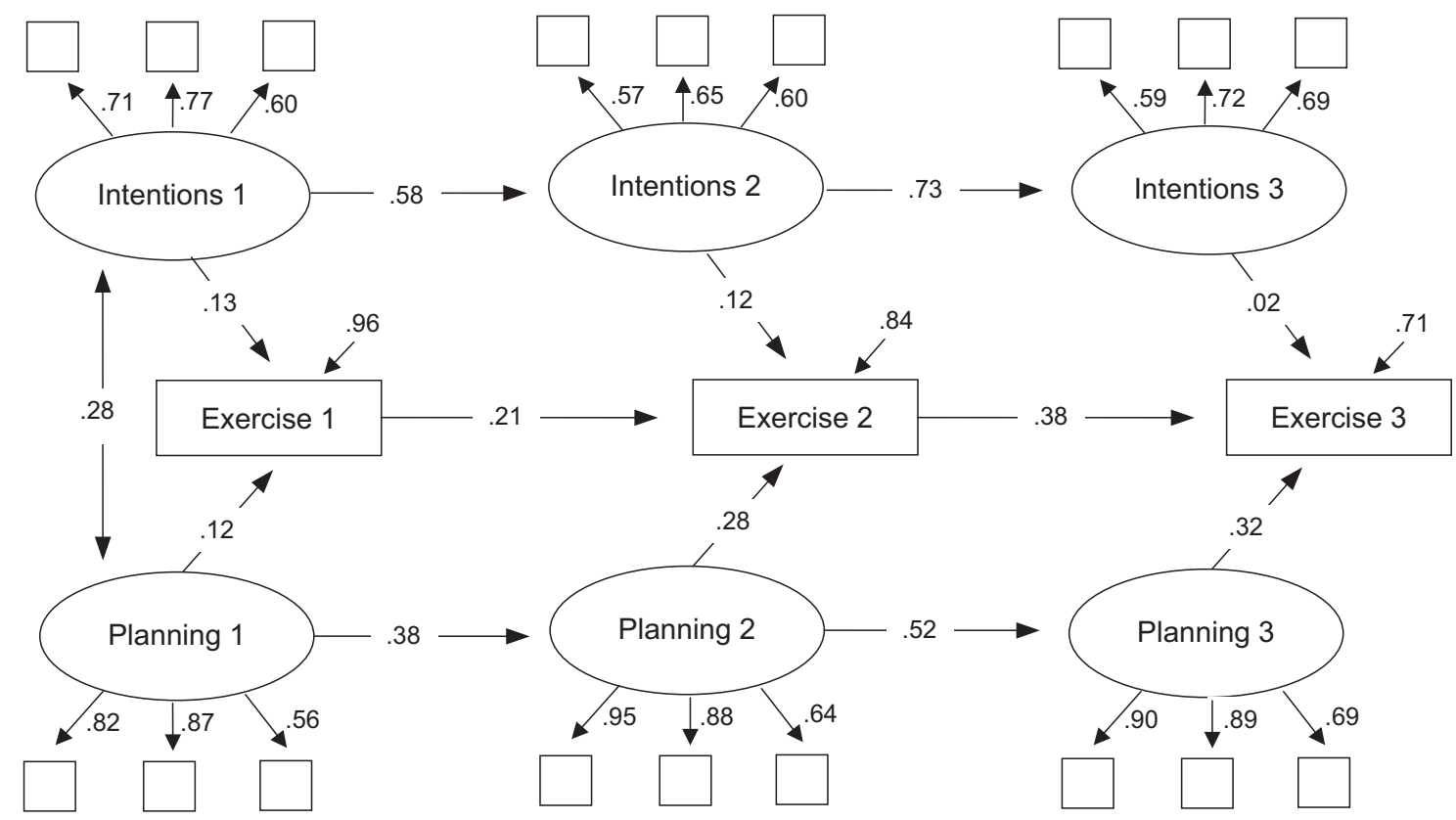

Figure 1. Figure 1 shows the structural equation model we used to predict physical exercise at three points in time according to goal intentions and implementation intentions. All path coefficients (the numbers shown on the arrows) are significant at $p<.05$, except for the one from Intentions 3 to Exercise 3 . The open squares are the indicator variables for the latent variables. Intentions $1=$ participants' goal intentions at the initial assessment (Time 1); Intentions 2 = participants' goal intentions at the 6-months follow-up (Time 2); Intentions $3=$ participants' goal intentions at the 12-months follow-up (Time 3); Exercise $1=$ participants' exercise behavior at Time 1; Exercise 2 = participants' exercise behavior at Time 2; Exercise $3=$ participants' exercise behavior at Time 3; Planning 1 = participants' implementation intentions at Time 1; Planning 2 = participants' implementation intentions at Time 2; Planning 3 = participants' implementation intentions at Time 3. 
(path coefficient $=.02, n s$ ). To determine whether paths were different, we used a nested model to test the null hypothesis that both predictors were equally strong. The comparison between the hypothesized model (no paths constrained to be equal) and the nested model (with respective paths constrained to be equal) revealed a significant difference only at $\mathrm{T} 3, \chi^{2}(1, N=368)=$ $6.18, p=.01 ; \Delta$ Tucker-Lewis index $=.002$. Thus, although there was a corresponding trend at T2 (path coefficient of .28 vs. .12), the superiority of implementation intentions over goal intentions became significant at T3 (path coefficient of .32 vs. .02) only.

\section{Discussion}

After a host of experimental studies have demonstrated the usefulness of implementation intentions (cf. Gollwitzer \& Sheeran, 2006), the present study is among the few that have used longitudinal designs to generalize the previous evidence to health behavior in the field of rehabilitation. A sample of 368 individuals participating in orthopedic rehabilitation was studied at three points in time in terms of participant's self-reported exercise intentions, planning, and exercise behaviors.

The first finding relates to changes at mean levels. There was an increase in exercise, whereas goal intentions and implementation intentions declined. This suggests that as behavior becomes more routinized, the level of cognitive control (by such factors as goal intentions or implementation intentions) may decline. Continuous, routinized exercise seems to become less dependent on both intentions and planning after a participant better integrates exercise into his or her lifestyle. This finding supports Ajzen's (2002) suggestion that as a behavior becomes routinized, less cognitive effort is required for its execution.

The second finding, based on structural equation modeling, provides a comparison of the predictive value of goal intentions with implementation intentions. Although there was no difference at $\mathrm{T} 1$, there was a clear superiority of implementation intentions over goal intentions at T2 and T3, which points one to the usefulness of implementation intentions. Levels of exercise behavior may still depend somewhat on planning even after the behavior becomes more routinized in the year after rehabilitation. As Ajzen (2002) proposed, "Once a behavior has become routine, the frequency of past behavior should be a good predictor of later behavior, but it should not eclipse the impact of intentions" ( $p$. 119).

Our study suggests that it may be implementation intentions rather than goal intentions that have an impact on behavior, even as behavior becomes more routinized. It is possible that, at the stage when behavior becomes routine, planning still predicts exercise behavior, as planning leads to mastery of the behavior, or conversely, that lack of planning results in the failure to exercise. If at this later stage behavior is still governed by cognitive factors, then these factors may refer to continuous self-regulatory efforts that include strategic planning. In contrast to relying on the more strenuous process of recalling intentions, planning is known to elicit behavior more or less automatically, thus conserving resources by not requiring much effort (Gollwitzer, 1999). In this line, Liu and Park (2004) have demonstrated that rehearsing intentions to complete the action did not enhance enactment as much as planning instructions did. Also, careful planning can limit a person to familiar and predictable situations for enacting the behavior, which should foster a sense of control (Fung, Abeles, \& Carstensen, 1999).

Autoregression coefficients of planning and intentions remained relatively high over 1 year. Behavioral stability may be attributed to the influence of cognitions that remain relatively stable over time (Ajzen, 2002). Stability of cognitions may promote behavior stability.

It is theoretically meaningful that planning is more predictive of exercise behavior when a person has high goal intentions as opposed to when a person is poorly motivated to exercise. Thus, the superiority of the planning construct in this study might be a result of sample selection. Individuals participating in rehabilitation are expected to be in a postintentional mindset, which means that they are motivated to exercise in order to regain their former strength and flexibility.

Potential limitations of this study should be discussed. First, the study is based on a convenience sample, and not all participants were available for follow-up; thus the generalizability of the present findings might be limited. However, we have demonstrated that, in terms of their functional status (i.e., scores on the SF-12), the participants were comparable to a German norm sample of individuals with an orthopedic condition (i.e., arthritis). In addition, we were able to demonstrate that study dropout was not systematic regarding the constructs of interest. Second, replication of this study in other samples of rehabilitation participants who suffer from other than orthopedic conditions is desirable. Third, further studies should include less motivated persons who are in an undecided, preintentional mind-set. In such a state, individual differences in goal intentions should allow for a better prediction of behaviors than individual differences in implementation intentions. Along this line, it has been demonstrated that implementation intentions are beneficial for goal attainment only in the presence of strong goal intentions (Sheeran, Webb, \& Gollwitzer, 2005). Fourth, although we have no direct measure of behavior routine or maintenance, Marcus et al. (2000) suggested a follow-up period of 6 months, which allows for the assessment of both initiation of and maintenance of health behaviors and which is in line with the definition of the maintenance stage of the transtheoretical model (Prochaska \& DiClemente, 1986). As the current study includes follow-ups over a 1-year period, we feel it is safe to interpret the reported behavior patterns as routine. Finally, the items used to measure cognitions that were incorporated in this study were endorsed on a 4-point scale. Hence, they provide polytomous data. Although the maximum-likelihood estimation method (used in this study) is robust in terms of the use of polytomous data (Lee, Poon, \& Bentler, 1992), future research should use the continuous-response format.

An implication for interventions lies in the tailoring of treatments to persons at different stages of health-behavior change (Nigg, 2003). Planning seems to be appropriate only in individuals who have reached a postintentional stage (Sheeran et al., 2005). Moreover, researchers have found it useful to subdivide the planning construct into action planning, in which individuals make when-where-how plans, and coping planning, in which individuals anticipate scenarios in which they cope with barriers by responding with tailored strategies (Lippke, Ziegelmann, \& Schwarzer, 2004; Scholz, Knoll, Sniehotta, \& Schwarzer, 2006; 
Sniehotta et al., 2005; Ziegelmann, Lippke, \& Schwarzer, 2006). Such strategic coping planning goes beyond the mere when, where, and how of action plans and is even more proximal to the performance of critical behaviors. Whereas a strenuous, controlled process such as recalling intentions is age-impaired, automatic processes, such as planning, seem to be largely age invariant (Park, 1999). In rehabilitation psychology, there is a need to identify interventions that "favourably influence the management of persons whose ability to control their own behaviour is compromised" (Grigsby, Kaye, Kowalsky, \& Kramer, 2002, p. 303). In this line, planning interventions that strengthen those automatic processes might be a powerful tool to overcome volitional problems across all age groups represented in rehabilitation settings.

\section{References}

Abraham, C., \& Sheeran, P. (2000). Understanding and changing health behavior: From health beliefs to self-regulation. In P. Norman, C. Abraham, \& M. Conner (Eds.), Understanding and changing health behavior (pp. 3-24). Amsterdam: Harwood Academic.

Ajzen, I. (2000). Theory of reasoned action. In A. E. Kazdin (Ed.), Encyclopedia of psychology (pp. 61-63). Washington, DC: American Psychological Association.

Ajzen, I. (2002). Residual effects of past on later behavior: Habituation and reasoned action perspectives. Personality and Social Psychology Review, 6, 107-122.

Arbuckle, J. L. (2003). Amos 5.0 user guide. Chicago: Small Waters.

Bernstein, M., Sloutskis, D., Kumanyika, S., Sparti, A., Schutz, Y., \& Morabia, A. (1998). Data-based approach for developing a physical activity frequency questionnaire. American Journal of Epidemiology, 147, 147-154.

Blanchard, C. M., Courneya, K. S., Rodgers, W. M., Daub, B., \& Knapik, G. (2002). Determinants of exercise intention and behavior during and after phase 2 cardiac rehabilitation: An application of the theory of planned behavior. Rehabilitation Psychology, 47, 308-323.

Bullinger, M., \& Kirchberger, I. (1998). SF-36. Fragebogen zum Gesundheitszustand [SF-36 Questionnaire Concerning Health Status]. Göttingen, Germany: Hogrefe.

Clay, D. L., \& Hopps, J. (2003). Treatment adherence in rehabilitation: The role of treatment accommodation. Rehabilitation Psychology, 48, 215-219.

Fung, H. H., Abeles, R. P., \& Carstensen, L. L. (1999). Psychological control in later life: Implications for life-span development. In M. Lerner \& J. Brandtstädter (Eds.), Action and development: Origins and functions of intentional self-development (pp. 345-372). Thousand Oaks, CA: Sage.

Gollwitzer, P. M. (1993). Goal achievement: The role of intentions. In W. Stroebe \& M. Hewstone (Eds.), European review of social psychology (Vol. 4, pp. 141-185). Chichester, England: Wiley.

Gollwitzer, P. M. (1999). Implementation intentions: Strong effects of simple plans. American Psychologist, 54, 493-503.

Gollwitzer, P. M., \& Sheeran, P. (2006). Implementation intentions and goal achievement: A meta-analysis of effects and processes. Advances in Experimental Social Psychology, 38, 69-119.

Green, G. R., \& Washington, E. M. (2004). Behavioral programming and staff development in adult day care. In H. E. Briggs \& T. L. Rzepnicki (Eds.), Using evidence in social work practice: Behavioral perspectives (pp. 171-189). Chicago: Lyceum Books.

Grigsby, J., Kaye, K., Kowalsky, J. C., \& Kramer, A. M. (2002). Relationship between functional status and the capacity to regulate behavior among elderly persons following hip fracture. Rehabilitation Psychology, 47, 291-307.
Jackson, C., Lawton, R., Knapp, P., Raynor, D. K., Conner, M., Lowe, C., \& Closs, S. J. (2005). Beyond intention: Do specific plans increase health behaviours in patients in primary care? A study of fruit and vegetable consumption. Social Science \& Medicine, 60, 2383-2391.

Kanfer, F. (1977). The many faces of self-control, or behavior modification changes its focus. In R. B. Stuart (Ed.), Behavioral self-management. Strategies, techniques and outcomes (pp. 1-48). New York: Brunner/Mazel.

Lee, S. Y., Poon, W. Y., \& Bentler, P. M. (1992). Structural equation models with continuous and polytomous variables. Psychometrica, 57, 89-105.

Leventhal, H. (1970). Findings and theory in the study of fear communications. In L. Berkowitz (Ed.), Advances in experimental social psychology (Vol. 5, pp. 119-186). New York: Academic Press.

Lippke, S., Ziegelmann, J. P., \& Schwarzer, R. (2004). Initiation and maintenance of physical exercise: Stage-specific effects of a planning intervention. Research in Sports Medicine: An International Journal, 12, 221-240.

Liu, L. L., \& Park, D. C. (2004). Aging and medical adherence: The use of automatic processes to achieve effortful things. Psychology and Aging, 19, 318-325.

Luszczynska, A. (2006). An implementation intentions intervention, the use of a planning strategy, and physical activity after myocardial infarction. Social Science \& Medicine, 62, 900-908.

Luszczynska, A., \& Schwarzer, R. (2003). Planning and self-efficacy in the adoption and maintenance of breast self-examination: A longitudinal study on self-regulatory cognitions. Psychology \& Health, 18, 93-108.

Marcus, B. H., Dubbert, P. M., Forsyth, L. H., McKenzie, T. L., Stone, E. J., Dunn, A. L., \& Blair, S. N. (2000). Physical activity behavior change: Issues in adoption and maintenance. Health Psychology, 19(Suppl. 1), 32-41.

McMillan, T., \& Sparkes, C. (1999). Goal planning and neurorehabilitation: The Wolfson Neurorehabilitation Centre approach. Neuropsychological Rehabilitation, 9, 241-251.

Miller, W. R., \& Rollnick, S. (2002). Motivational interviewing: Preparing people for change (2nd ed.). New York: Guilford Press.

Milne, S., Orbell, S., \& Sheeran, P. (2002). Combining motivational and volitional interventions to promote exercise participation: Protection motivation theory and implementation intentions. British Journal of Health Psychology, 7, 163-184.

Nigg, C. R. (2003). Technology's influence on physical activity and exercise science: The present and the future. Psychology of Sport and Exercise, 4, 57-65.

Park, D. C. (1999). Aging and the controlled and automatic processing of medical information and medical intentions. In D. C. Park, R. Morrell, \& K. Shifren (Eds.), Processing of medical information in aging patients: Cognitive and human factors perspectives (pp. 3-22). Mahwah, NJ: Erlbaum.

Prochaska, J. O., \& DiClemente, C. C. (1986). Towards a comprehensive model of change. In W. R. Miller \& N. Heather (Eds.), Treating addictive behaviors: Processes of change (pp. 3-27). New York: Plenum Press.

Scholz, U., Knoll, N., Sniehotta, F. F., \& Schwarzer, R. (2006). Physical activity and depressive symptoms in cardiac rehabilitation: Long-term effects of a self-management intervention. Social Science \& Medicine, 62, 3109-3120.

Schwarzer, R. (1992). Self-efficacy in the adoption and maintenance of health behaviors: Theoretical approaches and a new model. In R. Schwarzer (Ed.), Self-efficacy: Thought control of action (pp. 217-243). Washington, DC: Hemisphere Publication Services.

Sheeran, P. (2002). Intention-behavior relations: A conceptual and empirical review. In M. Hewstone \& W. Stroebe (Eds.), European review of social psychology (Vol. 12, pp. 1-36). New York: Wiley. 
Sheeran, P., Webb, T. L., \& Gollwitzer, P. M. (2005). The interplay between goal intentions and implementation intentions. Personality and Social Psychology Bulletin, 31, 87-98.

Sniehotta, F. F., Schwarzer, R., Scholz, U., \& Schüz, B. (2005). Action plans and coping plans for long-term lifestyle change: Theory and assessment. European Journal of Social Psychology, 35, 565-576.

Sutton, S. (1998). Predicting and explaining intentions and behavior: How well are we doing? Journal of Applied Social Psychology, 28, 1317-1338.

Ware, J., Jr., Kosinski, M., \& Keller, S. D. (1996). A 12-item short-form health survey: Construction of scales and preliminary tests of reliability and validity. Medical Care, 34, 220-233.

Ziegelmann, J. P., Lippke, S., \& Schwarzer, R. (2006). Adoption and maintenance of physical activity: Planning interventions in young, middle-aged, and older adults. Psychology \& Health, 21, 145-163.

Received September 9, 2005

Revision received February 24, 2006

Accepted March 9, 2006 